\title{
Insufflation of Carbon Dioxide versus Air During Colonoscopy Among Pediatric Patients: A Systematic Review and Meta-Analysis of Randomized Controlled Trials
}

\author{
John Alexander Lata Guacho', Diogo Turiani Hourneaux de Moura ${ }^{1,4}$, Igor Braga Ribeiro', Bruna Furia Buzetti Hourneaux de \\ Moura ${ }^{2}$, Megui Marilia Mansilla Gallegos ${ }^{3}$, Thomas McCarty ${ }^{4}$, Ricardo Katsuya Toma ${ }^{2}$ and Eduardo Guimarães Hourneaux de Moura ${ }^{1}$ \\ ${ }^{1}$ Gastrointestinal Endoscopy Unit, ${ }^{2}$ Gastroenterology and Hepatology Pediatric Unit, Hospital das Clínicas da Faculdade de Medicina \\ da Universidade de São Paulo, São Paulo, Brazil, ${ }^{3}$ Servicio de Gastroenterología, Clínica Maison de Sante del Sur Lima-Perú, Lima, \\ Perú, ${ }^{4}$ Division of Gastroenterology, Hepatology and Endoscopy, Brigham and Women's Hospital, Boston, MA, USA
}

Background/Aims: Carbon dioxide is increasingly used in insufflation during colonoscopy in adult patients; however, air insufflation remains the primary practice among pediatric gastroenterologists. This systematic review and meta-analysis aims to evaluate insufflation using $\mathrm{CO}_{2}$ versus air in colonoscopies in pediatric patients.

Methods: Individualized search strategies were performed using MEDLINE, Cochrane Library, EMBASE, and LILACS databases following Preferred Reporting Items for Systematic Reviews and Meta-Analyses (PRISMA) guidelines and Cochrane working methodology. Randomized control trials (RCTs) were selected for the present meta-analysis. Pooled proportions were calculated for outcomes including procedure time and abdominal pain immediately and 24 hours post-procedure.

Results: The initial search yielded 644 records, of which five RCTs with a total of 358 patients $\left(\mathrm{CO}_{2}: n=178\right.$ versus air: $\left.n=180\right)$ were included in the final analysis. The procedure time was not different between the $\mathrm{CO}_{2}$ and air insufflation groups (mean difference, 10.84; $95 \%$ confidence interval [CI], -2.55 to $24.22 ; p=0.11$ ). Abdominal pain immediately post-procedure was significantly lower in the $\mathrm{CO}_{2}$ group (risk difference [RD], $-0.15 ; 95 \% \mathrm{CI} ;-0.26$ to $-0.03 ; p=0.01$ ) while abdominal pain at 24 hours post-procedure was similar (RD, $-0.05 ; 95 \% \mathrm{CI} ;-0.11$ to $0.01 ; p=0.11$ ).

Conclusions: Based on this systematic review and meta-analysis of RCT data, $\mathrm{CO}_{2}$ insufflation reduced abdominal pain immediately following the procedure, while pain was similar at 24 hours post-procedure. These results suggest that $\mathrm{CO}_{2}$ is a preferred insufflation technique when performing colonoscopy in pediatric patients. Clin Endosc 2021;54:242-249

Key Words: Air; Carbon dioxide; Colonoscopy; Meta-analysis; Pediatric

\section{INTRODUCTION}

Over the last 30 years, gastrointestinal endoscopy in pediatric patients has been increasingly developed to improve its

\footnotetext{
Received: October 14, 2020 Revised: January 26, 2021

Accepted: February 1, 2021

Correspondence: Igor Braga Ribeiro

Gastrointestinal Endoscopy Unit, Hospital das Clínicas da Faculdade de Medicina da Universidade de São Paulo, Av. Dr. Enéas de Carvalho Aguiar, 255, Instituto Central, Prédio dos Ambulatórios, São Paulo, 05403-000, Brazil

Tel: +55-92-98137-7788, Fax: +55-11-2661-6467, E-mail: igorbraga1@gmail.com ORCID: https://orcid.org/0000-0003-1844-8973

(c) This is an Open Access article distributed under the terms of the Creative Commons Attribution Non-Commercial License (http://creativecommons.org/ licenses/by-nc/3.0) which permits unrestricted non-commercial use, distribution, and reproduction in any medium, provided the original work is properly cited.
}

diagnostic and therapeutic utilities. ${ }^{1}$ Colonoscopy procedures for children are mainly performed for those suspected of inflammatory bowel disease, rectal bleeding, genetic polyposis syndromes, anemia, and unexplained chronic diarrhea. ${ }^{1}$ With fewer procedures performed in pediatrics compared to the adult population, mostly as a result of routine colorectal screening, careful consideration must be given regarding the procedure to achieve appropriate bowel preparation, reduce procedure-associated abdominal pain, safely administer anesthetic, and ensure cooperation among children and parents alike. $^{2-9}$

Since 1980, scientists have been investigating the impact of pain and pain relief among pediatric patients and the potential for negative physiological, emotional, and psychological 
ramifications. ${ }^{10-12}$ These findings suggest not only immediate impact but also lasting effects that alter the quality of life and the long-term future of many at-risk children. Given this, the American Academy of Pediatrics and the American Pain Board recommended the safe use of analgesics and pain relief whenever possible in the appropriate clinical setting. For this reason, techniques to reduce abdominal pain during colonoscopy have been implemented, such as the use of sedatives, hypnotics, acupuncture, Yoga nidra, music therapy, and the use of carbon dioxide. ${ }^{13,14}$

To date, novel advancements have been made in the diagnostic and therapeutic areas of endoscopy, including visualization of the intestinal mucosa and insufflation. ${ }^{15,16}$ Rogers ${ }^{17}$ conducted a small study that first reported on the benefit of using $\mathrm{CO}_{2}$ insufflation during colonoscopy, owing to the properties of fast absorption and improvement of adverse events caused by abdominal distention; since then $\mathrm{CO}_{2}$ has been used for a wide variety of endoscopic procedures. ${ }^{14,18-20}$ However, evidence for the use of $\mathrm{CO}_{2}$ insufflation during colonoscopies among pediatric population remains scarce, with data largely extrapolated from adults. The main objective of this study was to conduct a systematic review and meta-analysis of randomized controlled trials (RCTs) to assess the effectiveness of $\mathrm{CO}_{2}$ versus air insufflation in pediatric patients undergoing colonoscopy.

\section{METHODS}

\section{Protocol and registration}

This systematic review and meta-analysis was conducted following the guidelines of the Cochrane handbook for systematic reviews of interventions and information Elements (PRISMA, Preferred Reporting Items for Systematic Reviews and Meta-Aanalyses). ${ }^{21}$ This research work has been registered in the Prospective International Registry of Continuous Systematic Reviews of the National Institutes for Health Research (PROSPERO) with the code CRD42020185384. It also has the approval of the Committee of Scientific Ethics of the Department of Gastroenterology of the Faculty of Medicine from the University of São Paulo.

\section{Search and information sources}

The search strategy was carried out in the following electronic databases: MEDLINE, Cochrane Library, EMBASE, and LILACS from the start date to December 2020. Only RCTs were included, regardless of language and year of publication. The terminologies used for the search were the following in Medline: "(CO2 OR CO 2 OR carbon dioxide OR air OR insufflation / methods ${ }^{\star}$ ) AND (colonoscopy OR colonoscopic)
AND (pediatric OR pediatrics OR child OR preschool)". For other databases, the following search "Carbon Dioxide AND Air AND Colonoscopy" was used.

\section{Eligibility criteria, study selection, and data items}

RCTs using $\mathrm{CO}_{2}$ or air for colonoscopic insufflation in patients under 21 years old were included. Exclusion criteria were RCTs comprising patients with a history of cardiac health issues, acute pulmonary infections, chronic lung disease, oxygen-dependent pulmonary disease (such as bronchopulmonary dysplasia, severe asthma, or cystic fibrosis), mental disability, pregnancy, colon resection or stoma, known allergy to certain sedatives used during the procedure, inability to complete the visual analog scale or Wong-Baker Faces Scale, psychomotor impairment, or hemodynamic instability. Additionally, RCTs with patients undergoing colonic manometry were also excluded. Other exclusion criteria were case and series reports, editorial articles, and non-randomized studies (i.e., prospective or retrospective comparative studies). The outcomes measured in this study were the duration of the colonoscopy procedure, abdominal pain immediately after the procedure, and abdominal pain 24 hours after the procedure.

\section{Data collection process and study selection}

The information was collected from the selected clinical trials, contained in tables or graphs according to our results. Two independent investigators conducted the screening for eligibility with the criteria of inclusion and exclusion to our evaluation. Any disagreements were resolved by consensus or by consultation with a third reviewer. The data collected were type of study, patients by age, sex, total number, and indication of the examination.

\section{Risk of bias}

For the analysis of the risk of bias of the selected studies, using the Cochrane guidelines we assessed the adequate risk of bias exclusively for RCTs (Rob-2, risk-of-bias tool for RCTs), with the latest version updated on August 22, 2019..$^{22}$ When our study was included, the risk of bias analysis program classified it into five domains: selection of the reported result, measurement of the outcome, missing outcome data, deviations from intended interventions, randomization process, and overall. In addition, the characteristics for each domain were classified as low risk (green color), some concerns (yellow color), and high risk (red color) (Supplementary File 1), with the risks of bias that are assessed for each outcome and globally as described in the Cochrane Rob-2 guideline. ${ }^{22} \mathrm{We}$ performed complete analyses of individual studies and across the studies. 


\section{Synthesis of results, data analysis and summary measures}

\section{The rating of the evidence}

To qualify the evidence, it was evaluated using GRADEproGDT software (Mc Master University, Ontario, Canada). through objective analysis, according to the results of our study. GRADEproGDT is a software used to grade the evidence from included studies according to the following guidelines: number of studies, study design, risk of bias, imprecision, indirect evidence, inconsistency and other considerations, summary of findings, and importance.

The rating of the evidence and the risk of bias were guided and analyzed according to our statistical staff.

\section{Meta-analysis}

Statistical analysis was performed using the Cochrane RevMan 5 version 5.4 software (Cochrane Collaboration, Oxford, UK) that was updated in May 2020. Continuous variables were calculated by mean difference (MD) and 95\% confidence interval (CI) using a random effect with inverse variance while the risk of difference (RD) and 95\% CI for dichotomous variables were calculated using the Mantel-Haenszel method with a fixed effects model.

Heterogeneity was calculated using the Higgins method $\left(I^{2}\right)$. The values $<45 \%$ were considered as low heterogeneity, $46-75 \%$ as moderate heterogeneity, and $>75 \%$ as high heterogeneity. For the analyses, the mean, standard deviation, and absolute numbers were considered. When we had no means or standard deviations, they were calculated using mathematical equations. ${ }^{23} P$ values $\leq 0.05$ were considered statistically significant.

\section{RESULTS}

\section{Study selection}

When we placed the terms of our search strategy in the selected databases, 644 studies were identified. After analysis and confirmation of all the databases, duplicate articles were discarded, which were verified by titles and abstract comprising 522 articles, of which 46 were subsequently selected for manual verification of the complete literature. After the analysis of complete articles, seven studies were selected, of which two were excluded because they were not randomized controlled studies. Finally, we included five RCTs ${ }^{24-28}$ for analysis (Fig. 1).

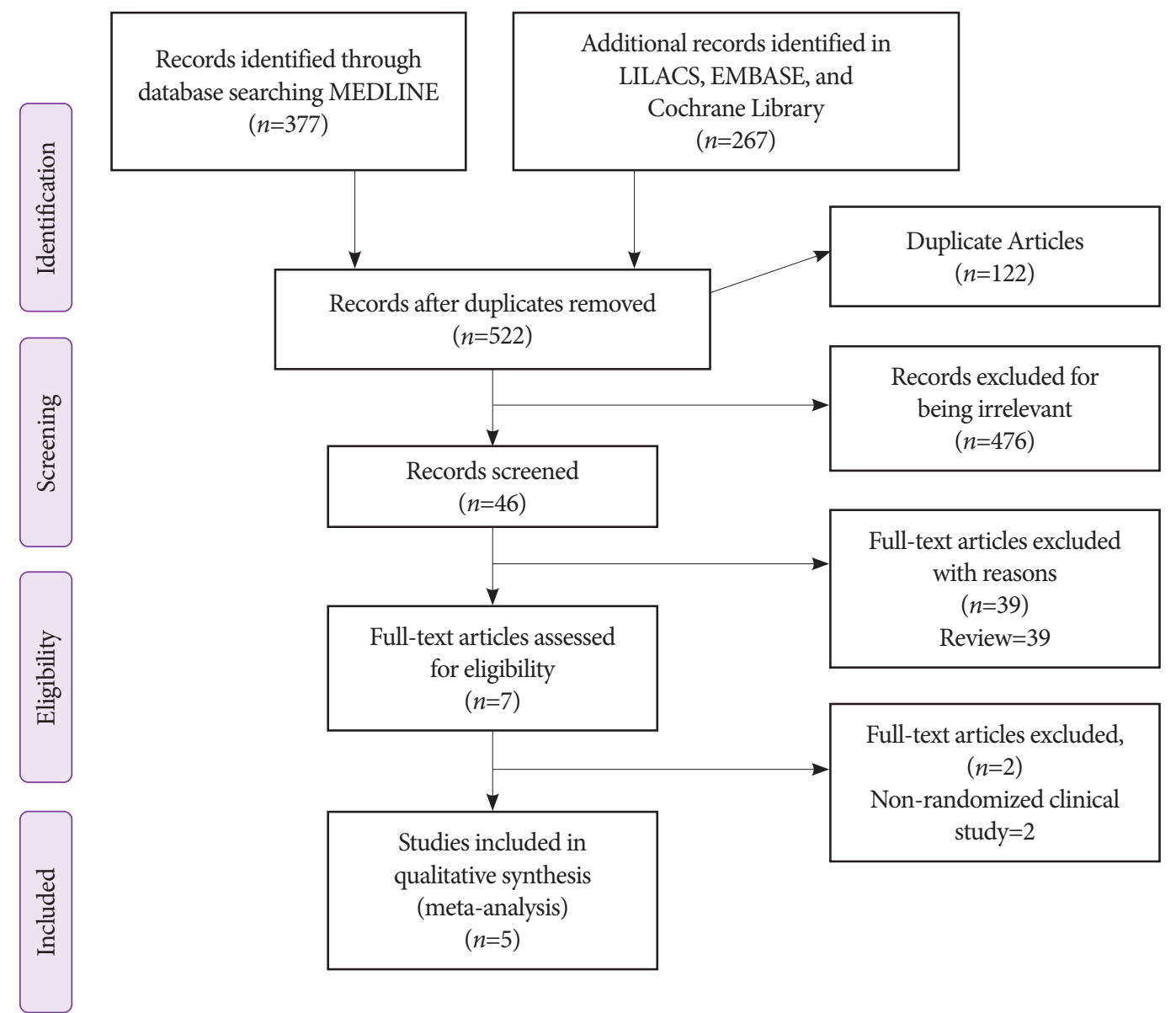

Fig. 1. Flow diagram of the analyzed studies. 
Table 1. Characteristics of Included Studies

\begin{tabular}{|c|c|c|c|c|c|c|c|c|}
\hline Study & Country & $\begin{array}{l}\text { Study } \\
\text { type }\end{array}$ & Blinding & Age (yr) & $\begin{array}{l}\text { Popula- } \\
\text { tion }(n)\end{array}$ & $\begin{array}{c}\text { Partic- } \\
\text { ipants } \\
\left(\mathrm{CO}_{2} / \text { Air }\right)\end{array}$ & Sedation and analgesia & Indications for colonoscopy \\
\hline $\begin{array}{l}\text { Dike et al. } \\
(2020)^{24}\end{array}$ & USA & $\mathrm{RCT}$ & Double & $\begin{array}{l}6 \text { months } \\
\text { to } 21\end{array}$ & 69 & $33 / 36$ & $\begin{array}{l}\text { Propofol and general } \\
\text { anesthesia administered } \\
\text { by pediatric anesthesiol- } \\
\text { ogist. }\end{array}$ & $\begin{array}{l}\text { Abdominal pain, diarrhea, } \\
\text { hematochezia, feeding or } \\
\text { growth concerns, other. }\end{array}$ \\
\hline $\begin{array}{l}\text { Dharmarj et } \\
\text { al. }\left(2020^{25}\right.\end{array}$ & USA & RCT & Double & $8-21$ & 100 & $48 / 52$ & $\begin{array}{l}\text { General anesthesia } \\
\text { administered by pedi- } \\
\text { atric anesthesiologist. } \\
\text { Sevoflurane and propo- } \\
\text { fol was used to obtain } \\
\text { a level of deep sedation } \\
\text { during the procedure. }\end{array}$ & $\begin{array}{l}\text { Chronic abdominal pain and } \\
\text { non-abdominal pain. }\end{array}$ \\
\hline $\begin{array}{l}\text { Kresz et al. } \\
(2019)^{26}\end{array}$ & Germany & RCT & Double & $4-17$ & 73 & $39 / 34$ & $\begin{array}{l}\text { Midazolam, propofol } \\
\text { and narcotics (alfentanil, } \\
\text { remifentanil, ketamine) } \\
\text { were administered by } \\
\text { an anesthesiologist to } \\
\text { maintain deep sedation. }\end{array}$ & $\begin{array}{l}\text { Inflammatory bowel disease } \\
\text { (active disease, evaluation } \\
\text { of therapy effectiveness), } \\
\text { chronic abdominal pain, } \\
\text { diarrhea, hematochezia and } \\
\text { other. }\end{array}$ \\
\hline $\begin{array}{l}\text { Thornhill et } \\
\text { al. }(2017)^{27}\end{array}$ & USA & RCT & Double & $5-18$ & 40 & $20 / 20$ & $\begin{array}{l}\text { General anesthesia ad- } \\
\text { ministered by pediatric } \\
\text { anesthesiologist. }\end{array}$ & $\begin{array}{l}\text { Abdominal pain, bleeding, } \\
\text { diarrhea, surveillance for } \\
\text { inflammatory bowel disease, } \\
\text { anemia, weight loss and } \\
\text { other. }\end{array}$ \\
\hline $\begin{array}{l}\text { Homan et al. } \\
(2016)^{28}\end{array}$ & USA & RCT & Double & $7-18$ & 76 & $38 / 38$ & Midazolam, ketamine. & $\begin{array}{l}\text { Chronic diarrhea, chronic } \\
\text { abdominal pain, suspicion of } \\
\text { inflammatory bowel disease, } \\
\text { inflammatory bowel disease } \\
\text { therapy effectiveness evalu- } \\
\text { ation, hematochezia, rectal } \\
\text { prolapse and malabsorption } \\
\text { syndrome. }\end{array}$ \\
\hline
\end{tabular}

RCT, randomized control trial.

\section{Study characteristics}

Five RCTs ${ }^{24-28}$ were included and 358 patients were identified: 178 in the $\mathrm{CO}_{2}$ insufflation group and 180 in the air insufflation group. The characteristics of the individual studies are listed in Table 1.

\section{Risk of bias}

On assessment of the risk of bias, the studies by Dike et al., ${ }^{24}$ Dharmarj et al., ${ }^{25}$ and Kresz et al. ${ }^{26}$ were considered low risk, whereas the studies by Thornhill et al. ${ }^{27}$ and Homan et al. ${ }^{28}$ had some concerns . Risk of bias was assessed globally and by outcomes (Supplementary File 1).

\section{Quality of evidence - GRADEpro}

The estimated outcome of procedure time demonstrated low-quality evidence. Abdominal pain immediately post-procedure showed high quality of evidence, while that at 24 hours after the procedure showed low quality of evidence (Supplementary File 2).

\section{Synthesis of results and results of individual studies}

\section{Procedure time}

Four studies ${ }^{24-26,28}$ in which 256 patients were included $\left(\mathrm{CO}_{2}\right.$ insufflation group, $n=127$; air insufflation group, $n=129$ ) re- 
ported the procedure time. In the statistical analysis, no statistical significance was shown between groups (MD, 10.84; 95\% CI, -2.55 to 24.22; $p=0.11$ ) (Fig. 2, Supplementary Fig. 1).

\section{Abdominal pain immediately post-procedure}

Three studies ${ }^{25-27}$ with a total of 213 patients $\left(\mathrm{CO}_{2}\right.$ insufflation group, $n=107$; air insufflation group, $n=106)$ reported the incidence of immediate abdominal pain post-colonoscopy. Abdominal pain was significantly higher in the air insufflation group than in the $\mathrm{CO}_{2}$ insufflation group (RD, $-0.15 ; 95 \% \mathrm{CI}$, -0.26 to $0.03 ; p=0.01$ ) (Fig. 3A, Supplementary Fig. 2).

\section{Abdominal pain at 24 hours post-procedure}

Three studies ${ }^{25,27,28}$ with 216 patients $\left(\mathrm{CO}_{2}\right.$ insufflation group, $n=106$; air insufflation group, $n=110$ ) reported adverse events of abdominal pain at 24 hours after colonoscopy. Statistical analysis did not show statistical significance between groups (RD, -0.05 ; 95\% CI, -0.11 to $0.01 ; p=0.11$ ) (Fig. 3B, Supplementary Fig. 3).

\section{DISCUSSION}

The role of colonoscopy in pediatric patients should include careful consideration of individual patient preference, be performed in a collaborative friendly environment, ensure the use of appropriate equipment, and be performed by a trained pediatric endoscopist. ${ }^{1,18,29}$ However, despite ensuring the most

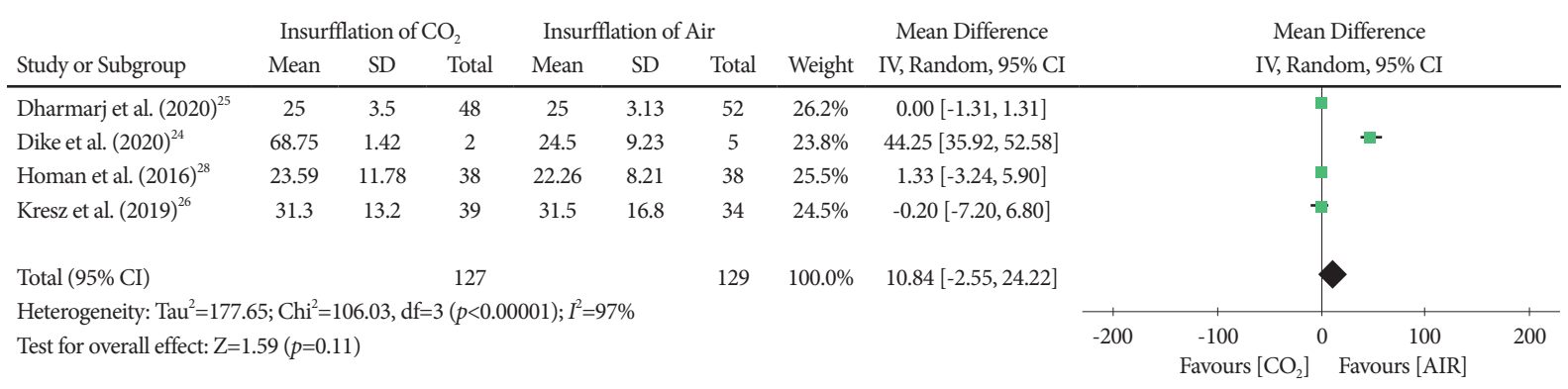

Fig. 2. Forest plot comparing the time of the colonoscopy procedure, using $\mathrm{CO}_{2}$ insufflation versus air insufflation in pediatric patients. $\mathrm{Cl}$, confidence interval; IV, instrumental variable; SD, standard deviation.

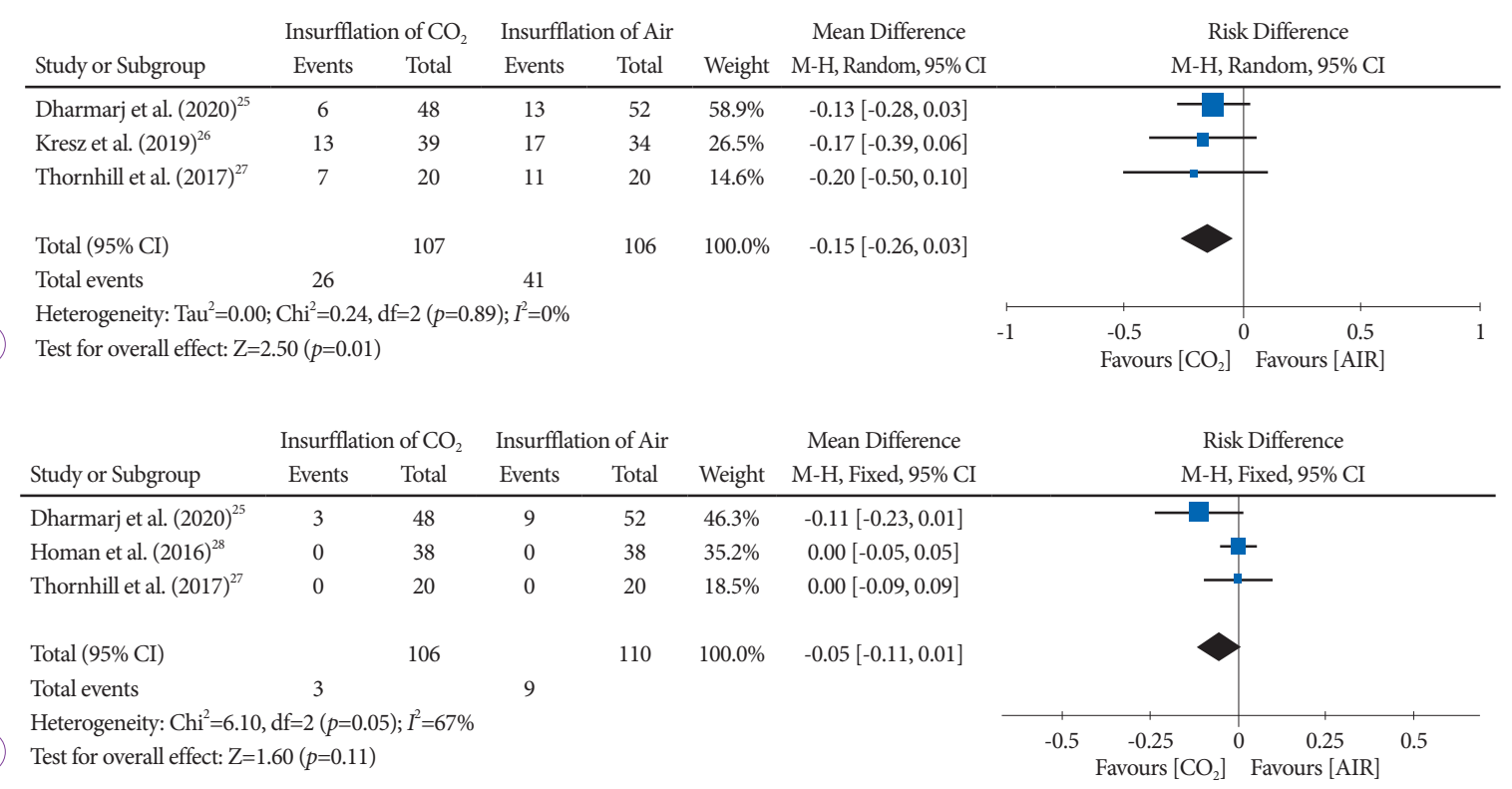

Fig. 3. (A) Forest plot comparing abdominal pain immediately post-procedure using $\mathrm{CO}_{2}$ insufflation versus air insufflation in pediatric patients. (B) Forest plot comparing abdominal pain at 24 hours after the procedure, using $\mathrm{CO}_{2}$ insufflation versus air insufflation in pediatric patients. $\mathrm{Cl}$, confidence interva. 
appropriate techniques and maneuvers during the procedure, colonoscopy may sometimes be associated with discomfort, mainly abdominal pain or bloating as a result of accumulation of gases used for insufflation. As such, the use of $\mathrm{CO}_{2}$, which is absorbed from the intestine into the blood 13 times faster than oxygen and 160 times faster than nitrogen may have distinct advantages over traditional air insufflation. ${ }^{30}$ In addition to having high diffusibility, $\mathrm{CO}_{2}$ may be easily excreted by the lungs, reducing gas volume after colonoscopy, allowing the intestine to decompress more quickly and potentially decrease intraprocedural and post-procedure pain, ${ }^{13,31,32}$ which is why insufflation with ambient air is increasingly being replaced by $\mathrm{CO}_{2}$.

We decided to conduct the first systematic review with meta-analysis comparing the benefits of $\mathrm{CO}_{2}$ versus ambient air insufflation during pediatric colonoscopy. In this study, we included five RCTs ${ }^{24-28}$ with good quality and adequate methodological design, including 358 pediatric patients. Furthermore, it was found that there was no statistical difference in terms of colonoscopy time, demonstrating that the type of gas used during the procedure does not influence the duration of the procedure. Additionally, based on this meta-analysis, post-procedure pain was also analyzed and $\mathrm{CO}_{2}$ insufflation showed clinical advantage in terms of reducing immediate post-colonoscopy abdominal pain in children.

These results are similar to those of several previous meta-analyses analyzing $\mathrm{CO}_{2}$ and air insufflation use in endoscopic procedures in adult patients. ${ }^{13,31,33,34}$ Despite this evidence, variable results have been found in pediatrics. In a pediatric study by Dharmaj et al. $2020,{ }^{25}$ multivariate analyses adjusted for baseline pain in children showed that $\mathrm{CO}_{2}$ insufflation only improved post-procedure pain in those patients with a history of abdominal pain, previous abdominal surgery, and procedures longer than 30 minutes. However, Dike et al. ${ }^{24}$ demonstrated minimal benefits in favor of $\mathrm{CO}_{2}$ in any pediatric endoscopic procedure. In a recent guideline published in 2020 , Rogers et al. ${ }^{34}$ evaluated 23 RCTs in adult patients undergoing colonoscopy to compare $\mathrm{CO}_{2}$ versus air insufflation and found that patients who underwent colonoscopy with air insufflation had 30\% higher intra-procedural pain scores than those who received $\mathrm{CO}_{2}$ insufflation. This study also demonstrated a sustained benefit in the $\mathrm{CO}_{2}$ group at 30 minutes, 1-2 hours, and 6 hours after the procedure $(p<0.001)$, as well as less abdominal distension, bloating, and flatulence.

While not assessed in our meta-analysis, four studies specifically evaluated abdominal bloating, ${ }^{24-26,28}$ showing no significant difference in bloating with $\mathrm{CO}_{2}$ versus ambient air insufflation during pediatric colonoscopy. This result is divergent from those analyzing adult patients, who demonstrated objectively decreased abdominal bloating post-procedure. ${ }^{34}$ While the mechanism for this difference remains unclear, it is worth noting that both groups of patients, children and adults, measured bloating via a tape measure to assess abdominal circumference. This crude, likely inaccurate method to assess bloating may explain these differences. Moreover, there are other more precise methods to measure bloating (i.e., validated questionnaires) or abdominal circumference, such as radiological measures; however, radiation exposure is not justifiable.

This meta-analysis did not find a significant difference in abdominal pain 24 hours post-colonoscopy between groups. However, the included studies assessed pain through telephone calls and questioning of the family members, thereby increasing the risk of bias. Several meta-analyses from adult populations have demonstrated decreased patient discomfort with $\mathrm{CO}_{2}$ insufflation, and therefore its use has been recommended in the British and European endoscopy guidelines for colonoscopy in adults. ${ }^{35-37}$ However, to date, pediatric endoscopy societies have not adopted $\mathrm{CO}_{2}$ insufflation into formalized guidelines, likely due to the low quality of evidence. ${ }^{1}$ The results obtained from this meta-analysis and systematic review, including only RCTs showed that the use of $\mathrm{CO}_{2}$ reduces post-procedure pain; we believe that future guidelines may recommend the use of $\mathrm{CO}_{2}$ as a preferred approach for colonoscopy procedures in the pediatric population.

Although this meta-analysis only included RCTs, our study is not without limitations. First, some patients included in this study underwent same-session upper digestive endoscopy in some cases using ambient air or $\mathrm{CO}_{2}$ for insufflation, which may interfere with the quantity of gas within the gastrointestinal lumen as well as alter the procedure time depending on the technique used to perform the colonoscopy, according to an experienced endoscopist or pediatric gastroenterology fellows. Second, the study by Dike et al. ${ }^{24}$ specifies the procedure time: only for upper digestive endoscopy, upper digestive endoscopy plus colonoscopy, and colonoscopy alone; taking into account that our meta-analysis included only colonoscopy, it is necessary for our evaluation to extract data only from the said procedure. Additionally, heterogeneity in trial design and lack of standardization in pain scales may also impact these results. Abdominal pain in the included studies was assessed using various pain scales, both numerical analog and visual, both of which are subjective measurements, thus promoting a heterogeneous analysis as most infants and young children cry before or after medical procedures by emotional stress of being with the healthcare staff, being in a different place or due to past traumatic experience and not necessarily related to the pain of the procedure. Additionally, procedural sedation may also impact the degree of post-procedure pain. Although 
procedural comfort and postprocedural pain are and should remain the most relevant outcomes of interest among a population of pediatric patients, a cost-effectiveness analysis of $\mathrm{CO}_{2}$ versus air insufflation may also be helpful to practitioners. Furthermore, although this meta-analysis included pediatric patients, patient age was over 10 years, necessitating more studies to specifically examine the impact of different insufflations in younger individuals. Lastly, despite the inclusion of five studies, not all studies provided relevant data for the measured outcomes of this meta-analysis. Nevertheless, this study is the first systematic review and meta-analysis to assess $\mathrm{CO}_{2}$ versus air insufflation during colonoscopy in a pediatric setting. Furthermore, the study was performed following the PRISMA guidelines and Cochrane working methodology.

In conclusion, $\mathrm{CO}_{2}$ insufflation significantly reduced the amount of post-procedure abdominal pain following colonoscopy. When compared to air insufflation for colonoscopy among a group of pediatric patients, immediate abdominal pain was decreased for patients undergoing $\mathrm{CO}_{2}$, with no change in procedure time or pain at 24 hours post-procedure. These findings suggest that $\mathrm{CO}_{2}$ insufflation should be the method of choice in pediatric colonoscopy.

\section{Conflicts of Interest}

Eduardo Guimarães Hourneaux de Moura received personal fees from Boston Scientific and Olympus, outside the submitted work. The other authors have no potential conflicts of interest.

Funding

None.

\section{Author Contributions}

Conceptualization: John Alexander Lata Guacho, Diogo Turiani Hourneaux de Moura, Igor Braga Ribeiro

Data curation: JALG, DTHM, IBR, Bruna Furia Buzetti Hourneaux de Moura, Megui Marilia Mansilla Gallegos, Thomas McCarty, Ricardo Katsuya Toma

Formal analysis: JALG, DTHM, IBR, TM

MethodologyJALG, DTHM, IBR, TM

Project administration: Eduardo Guimarães Hourneaux de Moura

Resources: EGHM

Software: EGHM

Supervision: DTHM, EGHM

Validation: DTHM, IBR, EGHM

Visualization: DTHM, IBR, EGHM

Writing-original draft: JALG, DTHM, IBR, MMMG

Writing-review and editing: JALG, IBR

\section{ORCID}

John Alexander Lata Guacho: https://orcid.org/0000-0002-3842-0735 Diogo Turiani Hourneaux de Moura: https://orcid.org/0000-0002-7446-0355 Igor Braga Ribeiro: $\quad$ https://orcid.org/0000-0003-1844-8973 Bruna Furia Buzetti Hourneaux de Moura: https://orcid.org/0000-0003-1501-4344 Megui Marilia Mansilla Gallegos: https://orcid.org/0000-0001-9318-3720 Thomas McCarty: https://orcid.org/0000-0003-4517-5261
Ricardo Katsuya Toma:

https://orcid.org/0000-0003-3792-8075

Eduardo Guimarães Hourneaux de Moura: https://orcid.org/0000-0002-8023-3722

\section{REFERENCES}

1. Thomson M, Tringali A, Dumonceau J-M, et al. Paediatric gastrointestinal endoscopy. J Pediatr Gastroenterol Nutr 2017;64:133-153.

2. Kiani M-A, Khodadad A, Mohammadi S, et al. Effect of peppermint on pediatrics' pain under endoscopic examination of the large bowel. J HerbMed Pharmacol 2013;2:41-44

3. Yoshioka S, Takedatsu H, Fukunaga S, et al. Study to determine guidelines for pediatric colonoscopy. World J Gastroenterol 2017:21;23:5773.

4. Rocha RS de P, Ribeiro IB, de Moura DTH, et al. Sodium picosulphate or polyethylene glycol before elective colonoscopy in outpatients? a systematic review and meta-analysis. World J Gastrointest Endosc 2018: $16 ; 10: 422-441$

5. de Moura DT, Guedes H, Tortoretto V, et al. [Comparison of colon-cleansing methods in preparation for colonoscopy-comparative of solutions of mannitol and sodium picosulfate]. Rev Gastroenterol Peru 2016;36:293-297.

6. Chen Y-J, Lee J, Puryear M, et al. A Randomized controlled study comparing room air with carbon dioxide for abdominal pain, distention, and recovery time in patients undergoing colonoscopy. Gastroenterol Nurs 2014;37:273-278.

7. Kim SY, Chung J-W, Park DK, et al. Comparison of carbon dioxide and air insufflation during consecutive EGD and colonoscopy in moderate-sedation patients: a prospective, double-blind, randomized controlled trial. Gastrointest Endosc 2017;85:1255-1262.

8. Fernández-Calderón M, Muñoz-Navas MÁ, Carrascosa-Gil J, et al. Carbon dioxide vs. air insufflation in ileo-colonoscopy and in gastroscopy plus ileo-colonoscopy: a comparative study. Rev Esp Enferm Dig 2012;104:237-241.

9. de Miranda Neto AA, de Moura DTH, Hathorn KE, Tustumi F, de Moura EGH, Ribeiro IB. Efficacy and patient tolerability of split-dose sodium picosulfate/magnesium citrate (SPMC) oral solution compared to the polyethylene glycol (PEG) solution for bowel preparation in outpatient colonoscopy: an evidence-based review. Clin Exp Gastroenterol 2020;13:449-457.

10. Victoria NC, Murphy AZ. Exposure to early life pain: long term consequences and contributing mechanisms. Curr Opin Behav Sci 2016;7:61-68.

11. Lee GY, Yamada J, Kyololo O, Shorkey A, Stevens B. Pediatric clinical practice guidelines for acute procedural pain: a systematic review. Pediatrics 2014;133:500-515.

12. Kiani MA, Heydarian F, Feyzabadi Z, Saeidi M, Jafari SA, Hebrani P. Effect of music and toys on reducing pain during colonoscopy and acceptance of colonoscopy by children: a randomized clinical trial. Electron physician 2019;11:7652-7659.

13. Memon MA, Memon B, Yunus RM, Khan S. Carbon dioxide versus air insufflation for elective colonoscopy. Surg Laparosc Endosc Percutan Tech 2016;26:102-116.

14. Nishizawa T, Suzuki H, Fujimoto A, Ochiai Y, Kanai T, Naohisa Y. Effects of carbon dioxide insufflation in balloon-assisted enteroscopy: a systematic review and meta-analysis. United Eur Gastroenterol J 2016;4:11-17.

15. Nambu R, Hagiwara S-I, Kakuta F, et al. Current role of colonoscopy in infants and young children: a multicenter study. BMC Gastroenterol 2019;19:149.

16. Ribeiro IB, Moura DTH de, Thompson CC, Moura EGH de. Acute abdominal obstruction: colon stent or emergency surgery? an evidence-based review. World J Gastrointest Endosc 2019;11:193-208.

17. Rogers $\mathrm{BH}$. The safety of carbon dioxide insufflation during colonoscop- 
ic electrosurgical polypectomy. Gastrointest Endosc 1974;20:115-117.

18. Dellon ES, Hawk JS, Grimm IS, Shaheen NJ. The use of carbon dioxide for insufflation during GI endoscopy: a systematic review. Gastrointest Endosc 2009;69:843-849.

19. Passos ML, Ribeiro IB, de Moura DTH, et al. Efficacy and safety of carbon dioxide insufflation versus air insufflation during endoscopic retrograde cholangiopancreatography in randomized controlled trials: a systematic review and meta-analysis. Endosc Int open 2019;7:E487E497.

20. Aquino JCM, Bernardo WM, de Moura DTH, et al. Carbon dioxide versus air insufflation enteroscopy: a systematic review and meta-analysis based on randomized controlled trials. Endosc Int Open 2018;06:E637E645.

21. Liberati A, Altman DG, Tetzlaff J, et al. The PRISMA statement for reporting systematic reviews and meta-analyses of studies that evaluate health care interventions: explanation and elaboration. J Clin Epidemiol 2009;62:e1-e34.

22. Sterne JAC, Savović J, Page MJ, et al. RoB 2: a revised tool for assessing risk of bias in randomised trials. BMJ 2019;366:14898.

23. Hozo SP, Djulbegovic B, Hozo I. Estimating the mean and variance from the median, range, and the size of a sample. BMC Med Res Methodol 2005;5:13.

24. Dike CR, Rahhal R, Bishop WP. Is carbon dioxide insufflation during endoscopy in children as safe and as effective as we think? J Pediatr Gastroenterol Nutr 2020;71:211-215.

25. Dharmaraj R, Dunn R, Fritz J, et al. Efficacy and safety of carbon dioxide versus air insufflation for colonoscopy in deeply sedated pediatric patients. J Pediatr Gastroenterol Nutr 2020;71:34-39 .

26. Kresz A, Mayer B, Zernickel M, Posovszky C. Carbon dioxide versus room air for colonoscopy in deeply sedated pediatric patients: a randomized controlled trial. Endosc Int Open 2019;07:E290-E297.

27. Thornhill C, Navarro F, Alabd Alrazzak B, et al. Insufflation with carbon dioxide during pediatric colonoscopy for control of postprocedure pain. J Clin Gastroenterol 2018;52:715-720.

28. Homan M, Mahkovic D, Orel R, Mamula P. Randomized, double-blind trial of $\mathrm{CO} 2$ versus air insufflation in children undergoing colonoscopy.
Gastrointest Endosc 2016;83:993-997.

29. de Moura DT, Guedes H, Tortoretto V, et al. Comparison of colon-cleansing methods in preparation for colonoscopy-comparative of solutions of mannitol and sodium picosulfate. Rev Gastroenterol Peru 2016;36:293-297.

30. Saltzman HA, Sieker HO. Intestinal response to changing gaseous environments: normobaric and hyperbaric observations. Ann N Y Acad Sci 1968;150:31-39.

31. Sajid MS, Caswell J, Bhatti MI, Sains P, Baig MK, Miles WFA. Carbon dioxide insufflation vs conventional air insufflation for colonoscopy: a systematic review and meta-analysis of published randomized controlled trials. Color Dis 2015;17:111-123.

32. Bassan MS, Holt B, Moss A, Williams SJ, Sonson R, Bourke MJ. Carbon dioxide insufflation reduces number of postprocedure admissions after endoscopic resection of large colonic lesions: a prospective cohort study. Gastrointest Endosc 2013;77:90-95.

33. Coronel M, Korkischko N, Bernardo WM, et al. Comparison between carbon dioxide and air insufflation in colonoscopy: a systematic review and meta-analysis based on randomized control trials. J Gastroenterol Pancreatol Liver Disord 2017;4:1-11.

34. Rogers AC, Van De Hoef D, Sahebally SM, Winter DC. A meta-analysis of carbon dioxide versus room air insufflation on patient comfort and key performance indicators at colonoscopy. Int J Colorectal Dis 2020;35:455-464.

35. Rutter MD, Chattree A, Barbour JA, et al. British Society of Gastroenterology/Association of Coloproctologists of Great Britain and Ireland guidelines for the management of large non-pedunculated colorectal polyps. Gut 2015;64:1847-1873.

36. Valori R, Rey J-F, Atkin W, et al. European guidelines for quality assurance in colorectal cancer screening and diagnosis. First Edition - Quality assurance in endoscopy in colorectal cancer screening and diagnosis. Endoscopy 2012;44(Suppl 3):SE88-SE105.

37. Paspatis GA, Dumonceau J-M, Barthet M, et al. Diagnosis and management of iatrogenic endoscopic perforations: European Society of Gastrointestinal Endoscopy (ESGE) Position Statement. Endoscopy 2014;46:693-711. 